\title{
Transient gene transfer and expression of Smad7 prevents bleomycin-induced lung fibrosis in mice
}

\author{
Atsuhito Nakao, ${ }^{1,2}$ Makiko Fujii, ${ }^{3}$ Ryutaro Matsumura, ${ }^{4}$ Kotaro Kumano, ${ }^{1}$ \\ Yasushi Saito, ${ }^{1}$ Kohei Miyazono, ${ }^{3}$ and Itsuo Iwamoto ${ }^{1}$ \\ ${ }^{1}$ Department of Medicine II, Chiba University, School of Medicine, Chiba 260-0856, Japan \\ ${ }^{2}$ Allergy Research Center, Juntendo University, School of Medicine, Tokyo 113-8421, Japan \\ ${ }^{3}$ Department of Biochemistry, The Cancer Institute, Japanese Foundation for Cancer Research, \\ Tokyo 170-8455, Japan \\ ${ }^{4}$ Department of Medicine, Toho University Medical School, Sakura Hospital, Chiba 285-0841, Japan
}

Address correspondence to: Atsuhito Nakao, Department of Medicine II, Chiba University, School of Medicine, 1-8-1, Inohana, Chiba City, Chiba 260-0856, Japan. Phone: 81-43-226-2093; Fax: 81-43-226-2095; E-mail: atuhito@intmed02.m.chiba-u.ac.jp.

Received for publication December 18, 1998, and accepted in revised form May 28, 1999.

TGF- $\beta$ plays an important role in lung fibrosis, which is a major cause of suffering and death seen in pulmonary disease. Smad 7 has been recently identified as an antagonist of TGF- $\beta$ signaling. To investigate whether this novel molecule can be exploited for therapy of lung fibrosis, we determined the effect of exogenous $S m a d 7$, introduced by a recombinant human type 5 adenovirus vector, on bleomycin-induced lung fibrosis in mice. C57BL/6 mice with bleomycin-induced lungs received an intratracheal injection of a recombinant adenovirus carrying mice $S m a d 7$ cDNA. These mice demonstrated suppression of type I precollagen mRNA, reduced hydroxyproline content, and no morphological fibrotic responses in the lungs when compared with mice administered adenovirus carrying $S m a d 6$ cDNA. In addition, we found that expression of Smad7 transgene blocked Smad2 phosphorylation induced by bleomycin in mouse lungs. These data indicated that gene transfer of $\operatorname{Smad} 7$ (but not Smad6) prevented bleomycin-induced lung fibrosis, suggesting that Smad7 may have applicability in the treatment of pulmonary fibrosis.

J. Clin. Invest. 104:5-11 (1999).

\section{Introduction}

TGF- $\beta$ plays an important role in the pathogenesis of lung fibrosis, which is a major cause of suffering and death seen in pulmonary medicine, based upon its strong extracellular matrix-inducing effect (1). It is thought that prolonged overproduction of TGF- $\beta$ induced by repeated chemical or biological injury leads to the accumulation of pathological amounts of extracellular matrix in the lung tissue, which is followed by functional deterioration (1). Association of TGF- $\beta$ with human lung fibrotic disorders has been demonstrated in idiopathic pulmonary fibrosis (2), autoimmune lung diseases (3), and bleomycin-induced lung fibrosis, which is also a frequently used model of lung fibrosis in animal experiments (4-7). In bleomycin-induced lung fibrosis in rodents, TGF- $\beta$ was shown to be required for the pathogenesis of the tissue fibrosis (8).

Recent studies have advanced our understanding of how TGF- $\beta$ mediates its biological effects. TGF- $\beta$ signals from membrane to nucleus using $\operatorname{Smad}$ proteins $(9,10)$. The activated TGF- $\beta$ receptors induce phosphorylation of $S$ mad2 and Smad3, which form hetero-oligomeric complexes with Smad4. The complexes then translocate to the nucleus and regulate transcriptional responses (9-12). Most recently, Smad7 has been identified as an intracellular antagonist of TGF- $\beta$ signaling; it inhibits TGF- $\beta$-induced transcriptional responses (13-15). $S m a d 7$ associates with the activated TGF- $\beta$ receptors and interferes with the activation of $S$ mad 2 and $S$ mad 3 by preventing their receptor interaction and phosphorylation. These basic findings suggest the therapeutic potential of the inhibitory Smad7 to prevent TGF- $\beta$-mediated lung fibrosis by the blockade of TGF- $\beta$ signaling.

To test the hypothesis, we determined the effect of exogenous Smad7 introduced by a recombinant human type 5 adenovirus vector (16) into the lungs on bleomycin-induced pulmonary fibrosis in mice in which TGF- $\beta$ was required for development of the tissue fibrosis (8). Our findings indicated that gene transfer of Smad7 prevented bleomycin-induced lung fibrosis in mice, suggesting that modulation of expression of $S \mathrm{mad} 7$ could be a novel approach to preventing lung fibrosis.

\section{Methods}

Adenovirus vector construction and virus purification. The recombinant E1-deleted adenoviral vectors carrying mouse Smad6 and Smad7 cDNA under cytomegalovirus promoters AdCMV-Smad6 and AdCMV-Smad7, respectively, were generated and purified as described previously (16-18). The Smad6/Smad7 cDNA was fused to the FLAG-epitope sequence, so that we were able to detect $S$ mad6/Smad7 protein derived from AdCMVSmad6/AdCMV-Smad7 by Western blotting with an antiFLAG antibody (Eastman Kodak Co. Scientific Imaging Systems, Rochester, New York, USA) (13). 
Experimental protocol. Bleomycin (100 mg/kg for 7 days; Sigma Chemical Co., St. Louis, Missouri, USA) was administered to female 8 to 10 -week-old C57BL/6 mice (Japan Charles River Inc., Yokohama, Japan) from days $0-7$ by a constant subcutaneous infusion by an osmotic minipump (Model 2001; Alza Corp., Palo Alto, California, USA) to induce lung fibrosis, as reported previously (19). To examine and compare the effect of exogenous Smad7 on lung fibrosis induced by bleomycin, mice were infected with the recombinant adenoviruses $A d C M V$ Smad7 or AdCMV-Smad6, using an intratracheal injection with $10^{9} \mathrm{pfu} /$ mouse, $8-12$ hours after initiation of bleomycin infusion at day 0 . Mice were sacrificed after 4 weeks (at day 28), and the lungs were fixed in $10 \%$ formalin for histological examination or were frozen

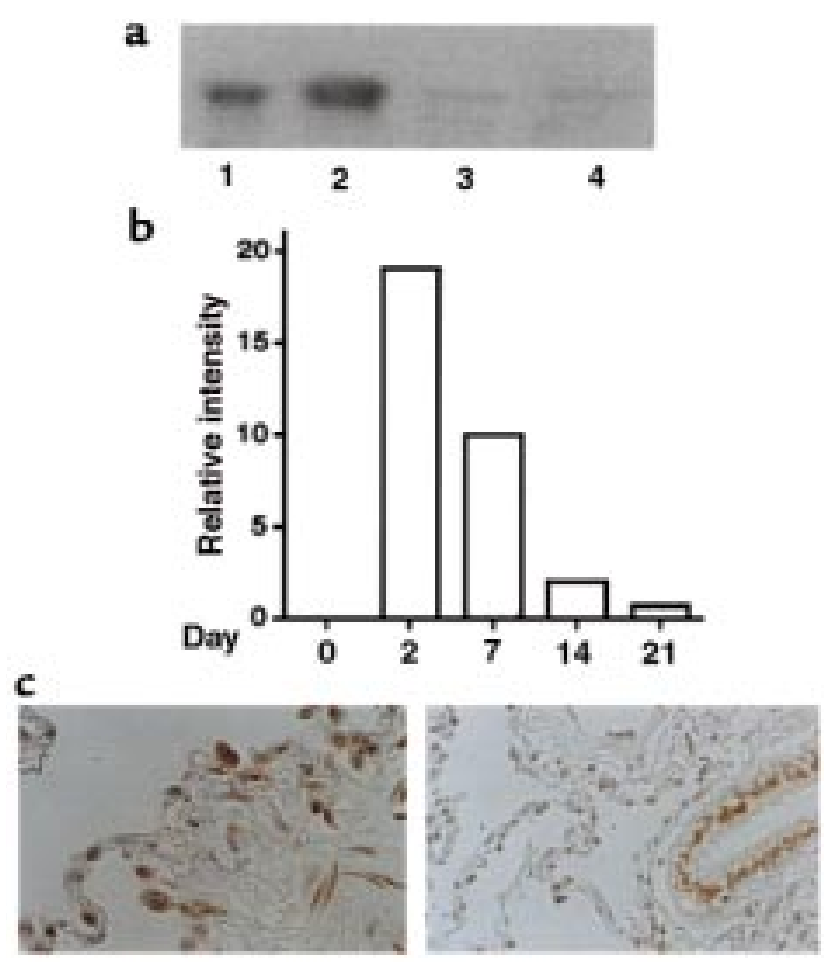

Figure 1

(a) Levels of immunoreactive $S m a d 7$ in the lungs of mice after treatment with bleomycin plus AdCMV-Smad7. Expression of exogenous Smad6 or Smad7 derived from an AdCMV-Smad6 or AdCMV-Smad7 construct was detected in the lungs (lane 1: Smad6; lane 2: Smad7), peripheral blood cells (lane 3: Smad7), and spleen (lane 4: Smad7) of bleomycin-treated mice at day 7 by Western blotting using anti-FLAG antibody after infection of AdCMV-Smad6 or AdCMV-Smad7 at day 0. (b) Quantitative analysis of expression of Smad7 transgene in the lungs of mice after treatment with bleomycin plus AdCMV-Smad7. Expression of Smad7 transgene was detected by Western blotting as shown in $\mathbf{a}$, and intensity of the bands of exogenous $\mathrm{Smad} 7$ detected at days $0,2,7,14$, and 21 was measured using NIH Image software. The relative intensity of the bands at indicated days was expressed as relative intensity compared with that at day 0 . (c) Cellular localization of Smad7 transgene in the lungs of mice after treatment with bleomycin plus AdCMV-Smad7. Immunohistochemical staining using anti-FLAG antibody was performed as described in the text. Staining was observed mainly in the nucleus of alveolar epithelial cells and interstitial fibroblast-like cells (left), and bronchial epithelial cells (right). immediately in liquid nitrogen and stored at $-80^{\circ} \mathrm{C}$ for Northern blot analysis. Measurements of hydroxyproline content in the mouse lungs were performed as described below. Animal experiments were approved by the Institutional Review Board of Chiba University.

Histological scoring of lung fibrosis in mice. Morphological evaluation of bleomycin-induced lung fibrotic responses in mice was performed using a semiquantitative fibrotic focus scoring method as reported previously by Lan Tran et al. (20). Briefly, the left lung of each mouse was fixed in 10\% formalin and stained with hematoxylin/eosin/safran for identification of lesions. In the hematoxylin-eosin-stained sections, viewed at $\times 400$, the lesions were defined as follows: absence of lesion $=0$; occasional small localized subpleural foci $=$ 1 ; thickening of interalveolar septa and subpleural foci $=2$; and thickened continuous subpleural fibrous foci and interalveolar septa $=3$. The sections were coded and examined in a blinded manner.

Northern blotting and Western blotting. Total RNA was extracted from the lungs, and Northern blotting for the detection of type I procollagen and TGF- $\beta_{1}$ mRNA was performed as described previously (21). The ${ }^{32} \mathrm{P}$ radioactivity associated with type I procollagen mRNA was quantitated by using a FujiX Bio-Imager (Fuji Photo Film Co., Tokyo, Japan) and was normalized by GAPDH mRNA levels. For Western blotting, the solubilized tissue homogenates $(50-100 \mu \mathrm{g})$ from freshly harvested lungs, spleens, and peripheral blood cells isolated by Ficoll-Plaque (Pharmacia-Upjohn, Uppsala, Sweden) were electrophoresed on an 8.5\% SDS-polyacrylamide gel and transferred to Immobilon-P (Millipore Corp., Bedford, Massachusetts, USA). Immunoblotting was performed using the antibodies against mouse Smad2 (Transduction Laboratories, Lexington, Kentucky, USA), phosphorylated Smad2, and an antiFLAG antibody as described previously (11). The antibody against phosphorylated $S$ mad 2 was raised after immunizing rabbits with the synthetic peptide (KKKSSMS) phosphorylated at the last 2 serine residues coupled to keyhole limpet hemocyanin, as reported previously (11). This phosphorylated peptide corresponds to the phosphorylation sites of Smad2, and the antibody specifically recognizes $S$ mad 2 phosphorylated by the TGF- $\beta$ type I receptor (22).

Hydroxyproline assay. Whole collagen content of the right lung was evaluated by determining hydroxyproline content (23). Briefly, after acid hydrolysis of the lung with $6 \mathrm{~N} \mathrm{HCl}$ at $110^{\circ} \mathrm{C}$ for 16 hours in a sealed glass tube, hydroxyproline content was determined by HPLC (24).

Bronchoalveolar lavage. To assess the effect of exogenous Smad7 on airway inflammation induced by bleomycin, leukocyte infiltration into bronchoalveolar lavage fluid (BALF) was evaluated at day 7 as described previously (25). Briefly, BALF was centrifuged at $400 \mathrm{~g}$ for $5 \mathrm{~min}$ utes at $4^{\circ} \mathrm{C}$, and cell differentials were determined by counting 500 cells stained with Wright-Giemsa solution. The supernatant of BALF at days 7 and 14 was stored at $-20^{\circ} \mathrm{C}$ for determination of TGF- $\beta$. 


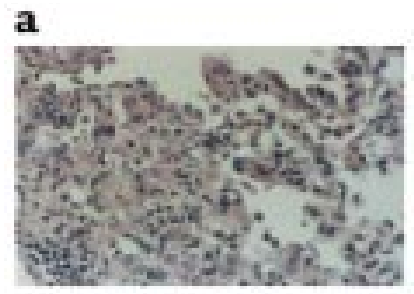

AdCMV-Smad6

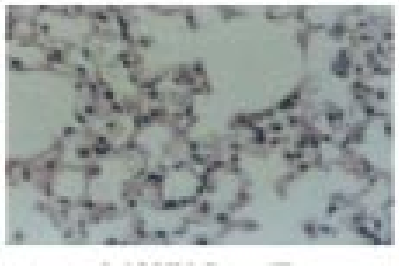

AdCMV-Smad7 b

\begin{tabular}{|c|c|c|c|c|c|}
\hline \multirow{2}{*}{ Treatment } & \multirow{2}{*}{$\begin{array}{l}\text { Number } \\
\text { of animals }\end{array}$} & \multicolumn{4}{|c|}{ Histology } \\
\hline & & so & s1 & 82 & $\$ 3$ \\
\hline PBS & 2 & 2 & & & \\
\hline $\begin{array}{l}\text { PBS } \\
+ \text { AdCMV-Smad6 }\end{array}$ & $16^{6}$ & 4 & 2 & & \\
\hline $\begin{array}{l}\text { PBS } \\
+ \text { AdCMV-Smad7 }\end{array}$ & $7^{6}$ & 5 & 1 & & \\
\hline Bløomycin & 6 & & & 1 & 5 \\
\hline $\begin{array}{l}\text { Bløomycin } \\
+ \text { AdCMV-Smad6 }\end{array}$ & 6 & & & 2 & 4 \\
\hline $\begin{array}{l}\text { Bleomycin } \\
+ \text { +AdCIAV-Smad7 }\end{array}$ & 6 & 3 & 2 & 1 & \\
\hline
\end{tabular}

\section{Figure 2}

Effect of exogenous Smad7 on bleomycin-induced lung fibrosis in mice. (a) Lung fibrosis was induced by continuous subcutaneous infusion of bleomycin ( $100 \mathrm{mg} / \mathrm{kg}$ for 7 days) from days $0-7$ in $\mathrm{C} 57 \mathrm{BL} / 6$ mice. Mice were infected with recombinant adenovirus (AdCMV-Smad6 or AdCMV-Smad7) by intratracheal injection with 109 $\mathrm{pfu} / \mathrm{mouse}$ at day 0 . Mice were sacrificed after 4 weeks, and the lungs were fixed in $10 \%$ formalin and stained with hematoxylin /eosin/safranin O. Left: treatment with bleomycin plus AdCMVSmad6. Note the thickened continuous interalveolar septa. Right: treatment with bleomycin plus AdCMV-Smad7. Note the absence of thickened interalveolar septa, although some increased cellularity in interalveolar septa was observed. (b) Scoring of lung fibrosis. Fibrotic changes in mouse lung ( $\mathrm{S} 0-\mathrm{S} 3=$ score $0-3$, respectively) were graded according to the criteria described in Methods.

TGF- $\beta$ levels in BALF. The amount of TGF- $\beta$ in the supernatant of BALF was measured by enzyme immunoassays using human TGF- $\beta_{1}$ ELISA kits (R\&D Systems Inc., Minneapolis, Minnesota, USA) that detect mouse TGF- $\beta_{1}$ protein, because of the high homology of TGF- $\beta_{1}$ across species. The assay detects only the active form of TGF- $\beta_{1}$. Samples were activated before measuring according to the manufacturer's recommendations. The sensitivity of this kit is $5 \mathrm{pg} / \mathrm{mL}$.

Immunohistochemical staining. The expression of exogenous $S m a d 7$ derived from the adenoviral vector was assessed at day 2 after initiation of bleomycin infusion by immunocytochemical staining, using optimally diluted biotinylated rabbit polyclonal anti-FLAG antibody (Santa Cruz Biotechnology Inc., Santa Cruz, California, USA) and rabbit serum (negative control) as described previously (26).
Statistical analysis. The statistical analyses of the results were performed using the Mann-Whitney $U$ test and by analyzing the variance using Fisher's least significant difference test for multiple comparisons. $P$ values less than 0.05 were considered to be significant.

\section{Results}

Expression of Smad7 transgene in mouse lungs. We first compared adenovirus vectors AdCMV-Smad7 or AdCMVSmad6 for their ability to express the transgenes in mouse lungs. Adenovirus vectors have been used for in vivo gene transfer to lungs as well as other organs (27). Smad6 has been shown to be another inhibitor of signaling used by the TGF- $\beta$ superfamily (9), but it preferentially inhibits signaling of bone morphogenetic protein (BMP) (28). Significant expression of exogenous Smad6 and Smad7 protein was detected in the lungs of mice treated with a subcutaneous infusion of bleomycin, followed by the administration of $A d C M V$ Smad6 or AdCMV-Smad7 by Western blotting using antiFLAG antibody at day 7 (Figure 1a). We found little or no expression of exogenous $S m a d 7$ in peripheral blood cells or spleen (Figure 1a). The expression levels of exogenous $\mathrm{Smad} 7$ in the lungs appeared to reach a peak at day 2 and persisted until day 21 (Figure 1b). Immunohistochemical staining using anti-FLAG antibody at day 2 showed that exogenous Smad7 protein was expressed in bronchial/alveolar epithelial cells and interstitial fibroblast-like cells (Figure 1c). The staining of exogenous $S \mathrm{mad} 7$ was observed mainly in the nucleus of those cells, which was in agreement with the findings by Itoh et al. (28). No staining was observed in the specimens using control rabbit antiserum (data not shown).

Effect of exogenous Smad7 on bleomycin-induced lung fibrosis in mice. Having demonstrated the ability of the $A d C M V$-Smad7 vector to express recombinant Smad7 transgene in the lungs, we sought to determine whether expression of the exogenous Smad7 could protect against lung fibrosis induced by bleomycin in mice.

Histological examination of lung specimens demonstrated that continuous subcutaneous bleomycin administration (100 mg/kg for 7 days) induced focal fibrotic lesions in mouse lungs, primarily in the subpleural regions with thickened or thickening interalveolar septa (data not shown), as reported previously (19). Treatment of mice with AdCMV-Smad6 did not significantly affect the lung fibrotic changes induced by bleomycin (Figure 2a). However, when mice were treated with AdCMV-Smad7 following administration of bleomycin, fibrotic lesions were less focal in the subpleural areas, and fibrotic changes in the interalveolar septa were less in degree (Figure 2a). Figure 2b summarizes the scoring of lung fibrotic changes as defined by the criteria described in Methods. Quantitative evaluation of the histological findings by scoring of fibrotic lesions showed significant suppression of bleomycininduced fibrotic changes by treatment of AdCMV-Smad7 $($ AdCMV-Smad6 treatment $=2.67 \pm 0.52$ mean $\pm \mathrm{SD}$; AdCMV-Smad7 treatment $=0.67 \pm 0.81$ mean $\pm \mathrm{SD} ; n=$ 
a

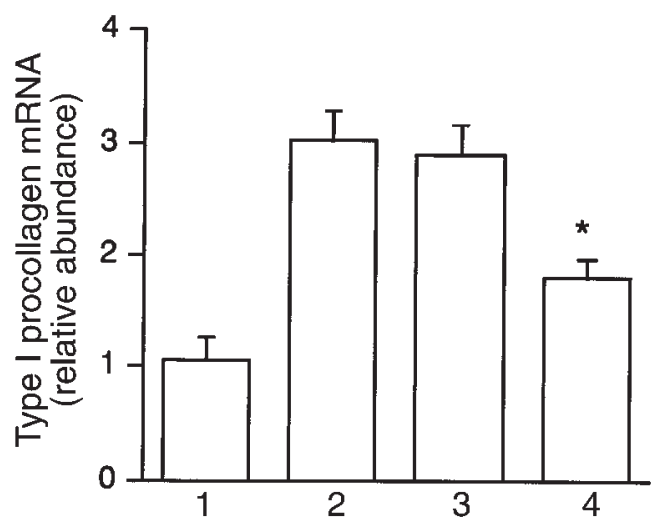

b

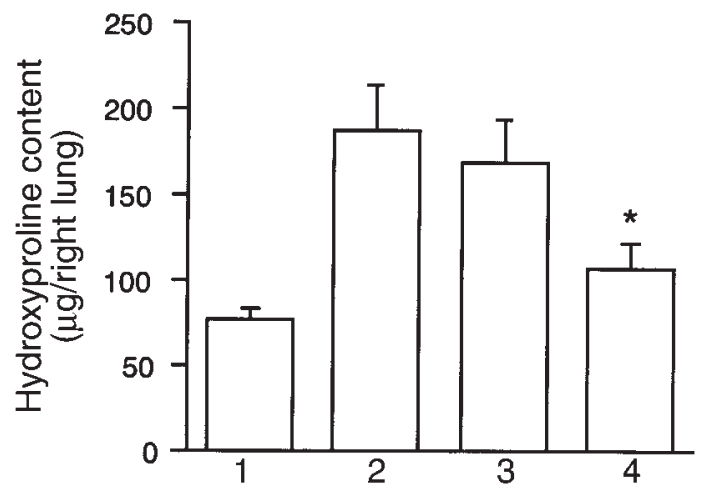

Figure 3

Effect of exogenous Smad7 on bleomycin-induced type I procollagen mRNA expression and hydroxyproline content in mouse lungs. (a) Quantitation of type I procollagen mRNA levels in the lungs removed at day 28. Bar 1: PBS-treated mice; bar 2: mice treated with bleomycin alone; bar 3: mice treated with bleomycin plus AdCMV-Smad6; bar 4: mice treated with bleomycin plus AdCMV-Smad7. Results are expressed as relative abundance of type I procollagen mRNA (type I procollagen mRNA/GAPDH mRNA) and are mean \pm SD for 6 mice in each group. * Result is significantly different $(P<0.005)$ from the mean value of the response (bleomycin alone or bleomycin plus AdCMV-Smad6). (b) Quantitation of hydroxyproline content at day 28 in the right lungs of PBS-treated mice (bar 1), mice treated with bleomycin alone (bar 2), mice treated with bleomycin plus AdCMV-Smad6 (bar 3), and mice treated with bleomycin plus AdCMV-Smad7 (bar 4). Results are mean \pm SD for 6 mice in each group. ${ }^{*}$ Result is significantly different $(P<$ $0.001)$ from the mean value of the response (bleomycin alone or bleomycin plus AdCMV-Smad6).

$6, P<0.01)$. In addition, significant fibrotic lesions were not noted in the lungs of mice that received recombinant adenoviral vectors alone, although some increased cellularity in interalveolar septa, suggesting minor inflammation, was observed (Figure 2b). These findings indicated that treatment of mice with AdCMV-Smad7 (but not AdCMV-Smad6) histologically suppressed bleomycin-induced fibrotic changes in mouse lungs.

Effect of exogenous Smad7 on type I procollagen $m R N A$ expression and hydroxyproline content in the lungs. To evaluate further the effect of Smad7 gene transfer on bleomycin-induced lung fibrosis, we assessed expression of type I procollagen mRNA and hydroxyproline content in the lungs. Uninjured lungs contained little type I procollagen mRNA, whereas type I procollagen
mRNA was upregulated in mice following bleomycin administration (Figure 3a), as described previously (6). There was significantly less type I procollagen mRNA in the lungs of mice treated with $A d C M V$-Smad7 after bleomycin administration, although treatment of mice with AdCMV-Smad6 did not affect expression of type I procollagen mRNA in the lungs after bleomycin administration (Figure 3a). Treatment of AdCMVSmad6 or AdCMV-Smad7 without bleomycin administration did not affect type I procollagen mRNA expression in the mouse lungs (data not shown).

Furthermore, we found that the hydroxyproline content was significantly lower in the lungs of mice treated with $A d C M V$-Smad7 after bleomycin administration than in those treated with $A d C M V$-Smad6 (Figure $3 \mathrm{~b}$ ). Treatment of mice with AdCMV-Smad6 did not affect lung hydroxyproline content in bleomycin-treated mice (Figure $3 \mathrm{~b}$ ). These findings indicated that expression of exogenous Smad7 suppressed the increase of type I procollagen mRNA expression and hydroxyproline content in the lungs of bleomycin-treated mice, which paralleled the morphological findings.

Effect of exogenous Smad7 on pulmonary inflammation and airway level of TGF- $\beta$. To determine whether exogenous $S$ mad7 affected bleomycin-induced pulmonary inflammation and TGF- $\beta$ production in mouse lungs, we examined the effect of exogenous $S m a d 7$ on the number of leukocytes and TGF- $\beta$ level in BALF of mice. As shown in Figure 4, a-c, we observed that subcutaneous infusion of bleomycin augmented the number of macrophages, lymphocytes, and neutrophils in BALF of the mice at day 7. Neither AdCMV-Smad7 nor AdCMV-Smad6 affected the number of macrophages, lymphocytes, and neutrophils in BALF of bleomycintreated mice at day 7 (Figure 4, a-c). TGF- $\beta$ level in BALF of bleomycin-treated mice was not detected at day 0 (data not shown) but was significantly increased at days 7 and day 14 (Figure $4 d$ ). No TGF- $\beta$ protein was detected in BALF of PBS-treated mice without, or infected with, $A d C M V$-Smad6/AdCMV-Smad7 at days 7 and 14 (data not shown). Treatment with $A d C M V$ Smad7 or AdCMV-Smad6 did not affect bleomycininduced TGF- $\beta$ production at days 7 and 14 in BALF of bleomycin-treated mice (Figure 4d). These findings indicated that expression of exogenous $\mathrm{Smad} 7 \mathrm{did}$ not affect bleomycin-induced pulmonary inflammation and TGF- $\beta$ production in mouse lungs.

Effect of exogenous Smad7 on bleomycin-induced Smad2 phosphorylation in mouse lung. Phosphorylation of Smad2 by the activated TGF- $\beta$ receptor is an important step for the initiation of TGF- $\beta$ signal transduction (11, 12). Smad7 associates with the activated TGF- $\beta$ receptors and interferes with the activation of Smad 2 by preventing its receptor interaction and phosphorylation, thereby antagonizing TGF- $\beta$ signaling $(13,14)$. Thus, we examined whether expression of Smad7 transgene inhibited Smad2 phosphorylation in the mouse lungs. We found, using an antibody against phosphorylated Smad2 for Western blotting, that Smad2 was phospho- 

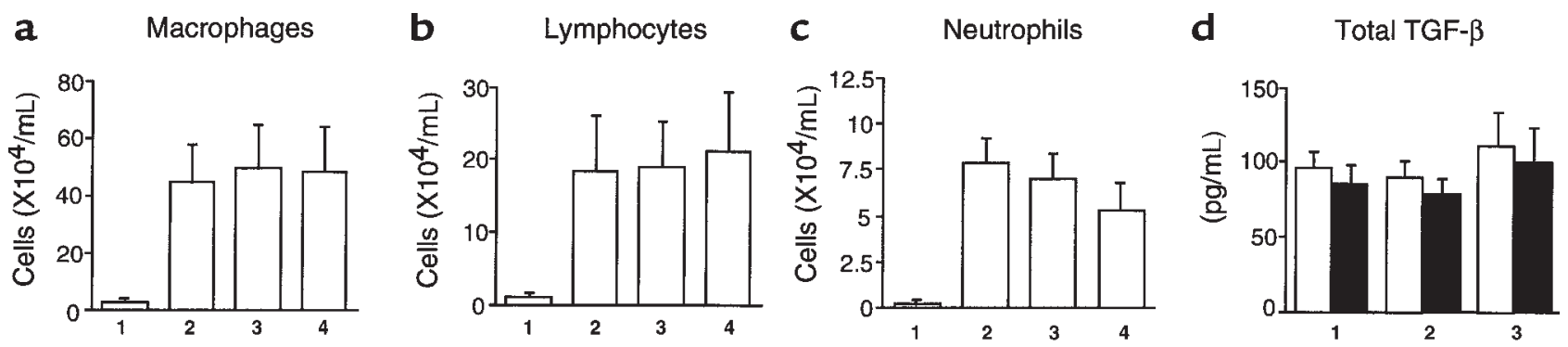

Figure 4

Effect of exogenous Smad7 on bleomycin-induced pulmonary inflammation and TGF- $\beta$ production in mouse lungs. (a-c). Leukocyte infiltration into BALF at day 7 of PBS-treated mice (bars 1), mice treated with bleomycin alone (bars 2), mice treated with bleomycin plus AdCMVSmad6 (bars 3), and mice treated with bleomycin plus AdCMV-Smad7 (bars 4). Results are means \pm SD for six 6 mice in each group. (d) Levels of TGF- $\beta$ in BALF at day 7 (open bars) and at day 14 (filled bars) of mice treated with bleomycin alone (bar 1 ), mice treated with bleomycin plus AdCMV-Smad6 (bar 2), and mice treated with bleomycin plus AdCMV-Smad7 (bar 3). Results are means \pm SD for 6 mice in each group.

rylated in the mouse lungs at day 7 after initial administration of bleomycin (Figure 5). When mice were treated with AdCMV-Smad7, this phosphorylation of $S m a d 2$ was inhibited (Figure 5). However, treatment of mice with AdCMV-Smad6 did not affect Smad2 phosphorylation in the mouse lungs induced by bleomycin (Figure 5). These data indicated that expression of exogenous Smad7 blocked Smad2 phosphorylation in the mouse lungs induced by bleomycin administration, suggesting that the effect of $S$ mad7 gene transfer was exerted at the level of this step for TGF- $\beta$ signal transduction in vivo.

\section{Discussion}

In this study, we showed that transient gene transfer and expression of $S$ mad7 (but not Smad6), introduced by recombinant human type 5 adenovirus vector into the lungs, prevented pulmonary fibrosis induced by bleomycin in mice, as demonstrated by tissue pathology, type I procollagen mRNA expression, and hydroxyproline content in the mouse lungs (Figures 2 and 3 ). We suggest that expression of exogenous $\mathrm{Smad} 7 \mathrm{might}$ exert its antifibrotic effect in mouse lungs by the blockade of Smad2 phosphorylation, the crucial step for initiation of TGF- $\beta$ signal transduction (Figure 5).

Smad7 has recently been identified (13-15), and the role of $S m a d 7$ as an intracellular inhibitor of TGF- $\beta$ signaling is well accepted $(28,29)$. However, the in vivo biological activity of the inhibitory Smad7 has not been defined yet. Our findings suggested that Smad 7 functioned as an antagonist of TGF- $\beta$ signaling in vivo.

In contrast, we found that exogenous Smad6 did not affect bleomycin-induced lung fibrosis in mice. Smad6 was originally identified as an inhibitor of signaling by the TGF- $\beta$ superfamily (30). However, recent studies suggested that Smad6 preferentially inhibited signaling of $\operatorname{BMP}(28,31)$, which might be consistent with our in vivo findings.

TGF- $\beta$ plays a critical role in bleomycin-induced lung fibrosis (4-8). Although the precise mechanisms of the lung fibrosis process remain unclear, Khalil et al. $(4,5)$ suggested that alveolar macrophages stimulated by bleomycin-induced injury secrete large quantities of TGF- $\beta$, thereby inducing lung fibroblasts in the alveolar interstitium to synthesize collagen, resulting in pulmonary fibrosis. Aside from the expected adenovectormediated expression of exogenous Smad7 in bronchial/alveolar epithelial cells, we found that exogenous $\mathrm{Smad} 7$ was expressed in interstitial fibroblast-like cells in lungs of mice treated with bleomycin (Figure 1). In addition, expression of exogenous Smad7 did not appear to affect bleomycin-induced pulmonary inflammation and TGF- $\beta$ production (Figure 4). Furthermore, recent studies showed that Smad2/Smad3 stimulated transcription of collagen genes $(32,33)$, and overexpression of Smad7 prevented the transcriptional activation of type I procollagen in human fibroblasts in vitro (33). Taken together, it is likely that expression of exogenous Smad7 prevented bleomycin-induced

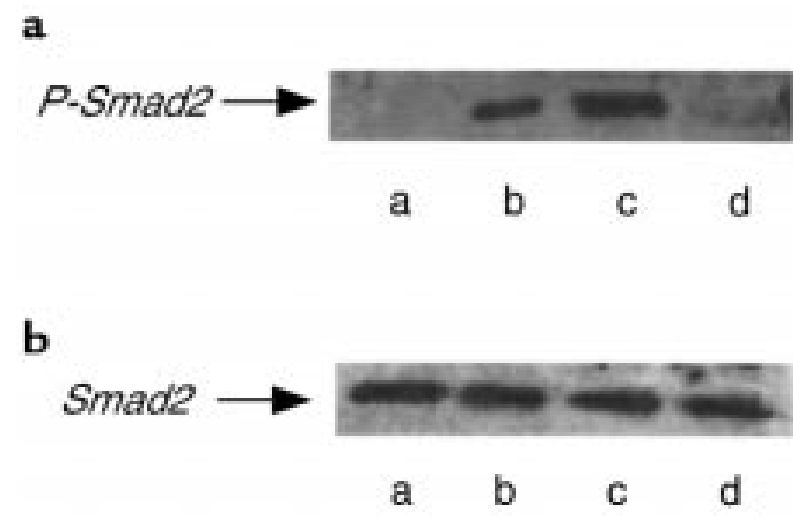

Figure 5

Effect of exogenous Smad7 expression on bleomycin-induced phosphorylation of Smad 2 in the mouse lungs. Levels of immunoreactive phosphorylated Smad2 (a) and Smad2 (b) in the lungs of PBS-treated mice (lane a), mice treated with bleomycin alone (lane b), mice treated with bleomycin plus AdCMV-Smad6 (lane c), and mice treated with bleomycin plus AdCMV-Smad7 (lane d). Lung samples were obtained at day 7 after initial administration of bleomycin. The same filter used in a was reprobed and blotted with Smad2 antibody. Exogenous Smad6 and Smad7 expression at day 7 was confirmed by Western blotting using anti-FLAG antibody as shown in Figure 1a. 
lung fibrosis by having a direct effect on collagen expression in mouse lungs. However, more studies are clearly required to define the exact site of $S$ mad7 action.

One possible Smad 7 action could be that expression of exogenous Smad7 may influence fibroblast chemotaxis that is important in developing tissue fibrosis in mouse lung (1). However, recent findings by Sime et al. (34) suggested that accumulation of fibroblasts/myofibroblasts in the lungs of bleomycin-treated rats was associated with upregulation of TGF- $\beta$ in the lungs. We found that TGF- $\beta$ levels in BALF of bleomycin-treated mice were not affected by gene transfer of $S$ mad6 or Smad7 (Figure 4). Thus, it may be unlikely that expression of exogenous Smad7 affects fibroblast migration in mouse lungs.

We found that the expression of exogenous Smad7 did not completely inhibit lung fibrosis induced by bleomycin (Figures 2 and 3). Since Itoh et al. (28) showed that the inhibitory effect of Smad7 on TGF- $\beta$ signaling was correlated with the expression level of Smad7 protein, one explanation could be that the expression level of Smad7 transgene was not sufficient to completely suppress TGF- $\beta$-induced pathways leading to collagen production in vivo. In addition, previous studies suggested the role of various cytokines in the development of lung fibrosis (35), including TNF $(34,36)$. Thus, it may be necessary to block the action of other cytokines, as well as TGF- $\beta$, to achieve complete inhibition of lung fibrosis.

In summary, we showed that transient gene transfer and expression of exogenous Smad7 (but not Smad6) into lung by adenoviral vectors prevented bleomycin-induced lung fibrosis, suggesting the therapeutic potential of Smad7 to prevent tissue fibrosis. Overproduction of TGF- $\beta$ is a chief cause of tissue fibrosis in various human fibrotic disorders, including those of the lung (1). Thus, the idea of using $\operatorname{Smad} 7$ as an antifibrotic agent would warrant investigation as a novel therapy for human fibrotic disorders. However, it is clear that we should develop strategies that promote gene-transfer efficiency before an investigation is initiated, because an adenovector-mediated approach has potential problems for application to human lung disorders in its present form (37). Furthermore, unfavorable consequences that might occur by long-term elimination of the TGF- $\beta$ effect, such as malignancy, must be investigated carefully.

\section{Acknowledgments}

We thank Peter ten Dijke for the generous gift of antibody against phosphorylated $S m a d 2$, and K. Kurasawa, H. Nakajima, T. Imamura, K. Kuroda, H. Endo, M. Mamura, K. Miyazawa, and I. Saito for valuable discussion and technical assistance. This work was supported in part by grants from the Ministry of Education, Science and Culture, Japan, and by a grant-in-aid from the Tokyo Biochemical Research Foundation (to A. Nakao).

\footnotetext{
1. Border, W.A., and Noble, N.A. 1994. Transforming growth factor $\beta$ in tissue fibrosis. N. Engl. J. Med. 10:1286-1292.

2. Broekelmann, T.J., Limper, A.H., Colby, T.V., and McDonald, J.A. 1991. Transforming growth factor- $\beta 1$ is present at sites of extracellular matrix
}

gene expression in human pulmonary fibrosis. Proc. Natl. Acad. Sci. USA. 88:6642-6646.

3. Deguchi, Y. 1992. Spontaneous increase of transforming growth factor- $\beta$ production by bronchoalveolar mononuclear cells of patients with systemic autoimmune diseases affecting the lung. Ann. Rheum. Dis. 51:362-365.

4. Khalil, N., Bereznay, O., Sporn, M., and Greenberg, A. 1989. Macrophage production of transforming growth factor- $\beta$ and fibroblast collagen synthesis in chronic pulmonary inflammation. J. Exp. Med. 170:727-737.

5. Khalil, N., Whitman, C., Zuo, L., Danelpour, D., and Greenberg, A. 1993. Regulation of alveolar macrophage transforming growth factor- $\beta$ secretion by corticosteroids in bleomycin-induced pulmonary inflammation in rats. J. Clin. Invest. 92:1812-1818.

6. Westergren-Thorsson, G., et al. 1993. Altered expression of small proteoglycans, collagen, and transforming growth factor- $\beta$ in developing bleomycin-induced pulmonary fibrosis in rats. J. Clin. Invest. 92:632-637.

7.Zhang, K., Flanders, K.C., and Phan, S.H. 1995. Cellular localization of transforming growth factor- $\beta$ expression in bleomycin-induced pulmonary fibrosis. Am. J. Pathol. 147:352-361.

8. Giri, S.N., Hyde, D.M., and Hollinge, M.A. 1993. Effect of antibody to transforming growth factor $\beta$ on bleomycin induced accumulation of lung collagen in mice. Thorax. 48:959-966.

9. Massagué, J. 1998. TGF- $\beta$ signal transduction. Annu. Rev. Biochem. 67:753-791.

10. Heldin, C.-H., Miyazono, K., and ten Dijke, P. 1997. TGF- $\beta$ signalling from the membrane to the nucleus through SMAD proteins. Nature. 390:465-473.

11. Nakao, A., et al. 1997. TGF- $\beta$ receptor mediated signalling through Smad2, Smad3, and Smad4. EMBO J. 16:5353-5362.

12. Macías-Silva, M., et al. 1996. MADR2 is a substrate of the TGF- $\beta$ receptor and its phosphorylation is required for nuclear accumulation and signaling. Cell. 87:1215-1224.

13. Nakao, A., et al. 1997. Identification of Smad7, a TGF--inducible antagonist of TGF- $\beta$ signalling. Nature. 389:631-635.

14. Hayashi, H., et al. 1997. The MAD-related protein Smad7 associates with the TGF- $\beta$ receptor and functions as an antagonist of TGF- $\beta$ signaling. Cell. 89:1165-1173.

15. Topper, J.N., et al. 1997. Vascular MADs: two novel MAD-related genes selectively inducible by flow in human vascular endothelium. Proc. Natl. Acad. Sci. USA. 94:9314-9319.

16. Niwa, H., Yamamura, K., and Miyazaki, J. 1991. Efficient selection for high-expression transfectants with a novel eukaryotic vector. Gene. 108:193-200.

17. Saito, I., Oya, Y., Yamamoto, K., Yuasa, T., and Shimojo, H. 1985. Construction of nondefective adenovirus type 5 bearing a 2.8-kilobase hepatitis B virus DNA near the right end of its genome. J. Virol. 54:711-719.

18. Miyake, S., et al. 1996. Efficient generation of recombinant adenoviruses using adenovirus DNA-terminal protein complex and a cosmid bearing the full-length virus genome. Proc. Natl. Acad. Sci. USA. 93:1320-1324.

19. Yaekashiwa, M., et al. 1997. Simultaneous or delayed administration of hepatocyte growth factor equally represses the fibrotic changes in murine lung injury induced by bleomycin. A morphological study. Am. J. Respir. Crit. Care Med. 156:1937-1944.

20. Lan Tran, P., et al. 1997. Prevention of bleomycin-induced pulmonary fibrosis after adenovirus-mediated transfer of the bacterial bleomycin resistance gene. J. Clin. Invest. 99:608-617.

21. Kuroda, K., and Shinkai, H. 1997. Gene expression of type I and III collagen, decorin, matrix metalloproteinases and tissue inhibitors of metalloproteinases in skin fibroblasts from patients with systemic sclerosis. Arch. Dermatol. Res. 289:567-572.

22. Persson, U., et al. 1998 . The L45 loop in type I receptors for TGF- $\beta$ family member is a critical determinant in specifying Smad isoform activation. FEBS Lett. 434:83-87.

23. Woessner, J.F., Jr. 1961. The determination of hydroxyproline in tissue and protein samples containing small proportions of this amino acid. Arch. Biochem. Biophys. 93:440-447.

24. Green, G.D., and Reagan, K. 1992. Determination of hydroxyproline by high pressure liquid chromatography. Anal. Biochem. 201:265-269.

25. Iwamoto, I., Kumano, K., Kasai, M., Kurasawa, K., and Nakao, A. 1996. Interleukin-12 prevents antigen-induced eosinophil recruitment into mouse airways. Am. J. Respir. Crit. Care Med. 154:1257-1260.

26. Nakajima, H., Sano, H., Nishimura, T., Yoshida, S., and Iwamoto, I. 1994. Role of VCAM-1/VLA-4 and ICAM-1/LFA-1 interactions in antigeninduced eosinophil and T cell recruitment into the tissue. J. Exp. Med. 179:1145-1154.

27. Brody, S.L., and Crystal, R.G. 1994. Adenovirus-mediated in vivo gene transfer. Ann. NY Acad. Sci. 716:90-101.

28. Itoh, S., et al. 1998. Transforming growth factor- $\beta 1$ induces nuclear export of inhibitory Smad7. J. Biol. Chem. 273:29195-29201.

29. Casellas, R., and Hammalti-Brivanlou, A. Xenopus Smad7 inhibits both the activin and BMP pathways and acts as a neural inducer. 1998. Dev. Biol. 198:1-12.

30. Imamura, T., et al. 1997. Smad6 inhibits signalling by the TGF- $\beta$ super- 
family. Nature. 389:622-626.

31. Hata, A., Lagna, G., Massague, M., and Hemmalti-Brivanlou, A. 1998 Smad6 inhibits BMP/Smad1 signaling by specifically competing with the Smad4 tumor suppressor. Genes Dev. 12:186-197.

32. Vindevoghel, L., et al. 1998. Smad-dependent transcriptional activation of human type VII collagen gene (COL7A1) promoter by transforming growth factor- $\beta$. J. Biol. Chem. 273:13053-13057.

33. Chen, S.J., et al. 1999. Stimulation of type I collagen transcription in human skin fibroblasts by TGF- $\beta$. J. Invest. Dermatol. 112:49-57.
34. Sime, P.J., et al. 1998. Transfer of tumor necrosis factor- $\alpha$ to rat lung induces severe pulmonary inflammation and patchy interstitial fibrogenesis with induction of TGF- $\beta 1$ and myofibroblasts. Am. J. Pathol. 153:825-832.

35. Kelley, J. 1990. Cytokines of the lung. Am. Rev. Respir. Dis. 141:765-768. 36. Piguet, P.F., et al. 1989. Tumor necrosis factor/cachectin plays a key role in bleomycin-induced pneumopathy and fibrosis. J. Exp. Med. 170:655-663.

37. Boucher, R.C. 1999. Status of gene therapy for cystic fibrosis lung disease. J. Clin. Invest. 103:441-445. 